\section{Waste Legislation and its Impact on Marketing Communication of the Circular Economy in Slovakia}

\author{
Dominik Jánoš \\ University of Ss. Cyril and Methodius in Trnava, Slovakia \\ https://orcid.org/0000-0003-2723-829X \\ Rudolf Rybanský \\ University of Ss. Cyril and Methodius in Trnava, Slovakia \\ https://orcid.org/0000-0001-6134-7137
}

Political Preferences

2020, vol. 26: 55-68 journals.us.edu.pl/index.php/PP Submitted: 02/06/2020 Accepted: 21/06/2020

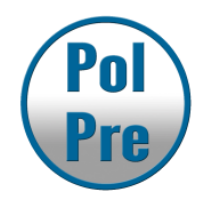

\begin{abstract}
:
The article focuses on the characteristics of circular economy, supporters of the concept of circular economy, legislation and marketing communication in the process of circular economy from theoretical perspective. In the practical part of the paper the results of marketing research are presented. Marketing research is divided into 3 phases and focused on whether the respondents from the sample follow the individual communication tools during the process of shopping for clothes. The aim of the paper is to analyze waste legislation by the means of marketing communication tools in the implementation of the cirucular economy in Slovakia.
\end{abstract}

Keywords: politics, legislation, marketing communication, waste management, circular economy, environment

\title{
Introduction
}

Nature and natural resources are an integral part of our being. They are a prerequisite for the functioning of the European and global economy and the basis of the quality of our lives. If current trends will continue, we can expect the world's population to increase by $30 \%$ by 2050 , representing around 9 billion people.

Over the last decade, we have witnessed the depletion of the resources and supplies that put enormous pressure on our planet. Future generations will no longer be able to use natural resources as much and as we do now. Increasing resource efficiency and securing jobs in Europe will be a response to these changes. Therefore, it is necessary to constantly develop new products and services and look for new ways to reduce inputs, minimize waste, improve resource management, change consumption patterns, optimize production processes and management and 
business methods, as well as improve logistics. All of this will help stimulate technological innovation, boost employment in the fast-growing green technology sector and boost trade in the EU, including the creation of new export markets, and benefit consumers through more sustainable products. A more efficient use of resources will help us to achieve our goals, which the EU has also set itself in the Europe 2020 strategy.

\section{Waste management policy}

The main objective of waste management policy should be to minimize the negative effects of the waste management on human health and environment. Waste management policy should also aim at reducing the use of natural resources and give priority to the practical application of the waste hierarchy in line with ,the polluter pays" principle. Waste prevention should be a top priority for waste management and the reuse and recycling of materials should be prioritized over the waste energy recovery, when it is possible and appropriate from an environmental, technical and economic point of view. Waste disposal should be the last option.

Waste management hierarchy:

- waste prevention,

- preparation for re-use,

- recycling,

- other recovery, e.g. energy,

- disposal.

The legal framework for the waste management in the European Union is laid down by the European Parliament and Council 2008/98/EC. The legal framework for waste management in the Slovak Republic is laid down by the Act of the National Council of the Slovak Republic No. 79/2015 Coll. on Waste and on amendments to certain acts, as amended (hereinafter referred to as the Waste Act). The Waste Act defines key terms, sets out basic requirements for waste management and the operators' obligations of facilities that perform waste management activities.

\section{Support systems}

In order to ensure the implementation of circular economy legal documents into production practice, EU Member States need to create an appropriate environment for an economy that uses the circular economy. This calls for a stronger link between the political direction of states, 
regulation of production and recycling, which can be achieved by significantly promoting innovation and research in this field.

If we want an answer to the question whether it is possible to realize such an ambitious plan of the EU on the market, to ensure an increased degree of reuse and quality recycling of waste, and simultaneously limit the dependence on primary resources - the answer would be unambiguous. The European Union has a complex system of support in various areas, such as regional and urban development, employment and social inclusion, agriculture, and rural development, maritime and fishing policy, research and innovations or humanitarian aid (Jánošová \& Labudová 2019). On the one hand, the European Union puts an effort to effectively using resources, can bring together and coordinate governments, as well as businesses and organisations, as well as it can summon the individual components of the economy to adopt measures that lead to the utilisation of the circular economy concept in the economy. On the other hand, there is the gigantic colossus of the linear economy and the free market, which constantly produces millions upon millions of products and it is precisely this colossus that helps to maintain both the European and global economy. It is unthinkable, that such an established system would give up without resistance, therefore legislative changes are the only means through which one can gradually regulate the amount of waste being created. To overcome the obstacles on the market, which in the present period is based on the linear principle of extract manufacture - consume, an entire system of measures within the EU is necessary. This entails mainly the issue that all markets are constantly urging to increase manufacturing productivity and these forms of the economy can lead to the endangerment of progress.

One of the most important supporters of the effective resource use and the circular economy are markets, because the material and energies became significant entries among the expenses of all companies. Although it is true that the markets are the driving force of change and growth, they simultaneously represent a whole set of obstacles, that create a barrier for efficient and effective management of resources. The European Commission has also gradually begun to apply specific legislative proposals that are focused on framework directives on waste, directives on landfills and directives focused on packaging and packaging waste, with the goal of transforming the economy in the European Union member states to a circular economy, and thus more effectivelly reuse waste for further usage on the market. „The transition to an economy that utilises a circular economic model is the foundation for the policy of effective resource use, as stipulated in the strategy Europe 2020 for securing intelligent, sustainable and inclusive growth." (Euractiv 2015). 
The change of waste into reusable resources is also the basic goal of the „Plan for effective resource use." This document stresses the necessity of paying more attention to the reuse and recycling of waste. „This plan strives to create an economy based on complete recycling, which involves the concept of a lifecycle, of better cooperation of all market entities within the value chain, better processes of gathering, an appropriate regulation framework, stimuli for preventing the creation of waste and recycling, as well as public investment into modern facilities for handling waste and high quality recycling. " (Euractiv 2015).

Since 2013 the European Union has been also gradually headed towards the creation of an economic system that utilises the concept of a circular economy. It actively participates in the utilisation of waste in the national economy of each state and on the solving of specific problems. Significant milestones in the realization of waste as an entry resource into the production process (according to Euractiv.sk 2015) of polyethylene bags in the member states of the European Union:

- June - September 2013: a public consultation was held on the revision of the European goals in waste management;

- July 2013: the European Commission (EC) presented a revision of the statute on the transport of waste;

- November 2013: the EC proposed the amendment of the directive on packaging and packaging waste, with the goal of decreasing the consumption of polyethylene bags in the EU member states;

- December - January 2013/2014: the EC published a detailed analysis of the project of revising the goals in the area of waste and waste management;

- 2015: The Commission reevaluated the measures and goals of the framework directive on waste, and if needed, set goals for further processing of waste;

- 2015: EU member states developed individual schemes for sorting collected paper, metals, plastics and glass;

- Until 2020: The EU has the stated goal of raising the reuse and recycling of waste from households to at least $50 \%$, based on the weight of the waste;

- Until 2020: The EU has the stated the goal of raising the reuse, recycling and other conversion of construction waste and demolition waste from to at least $70 \%$, based on the weight of the waste. 


\section{Legislation and marketing communication in the process of circular economy}

During the years 2018 - 2020, at the University of St. Cyril and Methodius in Trnava, we were conducting the research task VEGA project No. 1/0078/18 "Aspects of marketing communication in management processes of circular economy", which results are implemented in the solution of waste legislation and its impact on marketing communication in the circular economy in Slovakia.

The priority of a circular economy is a more economical and more effective utilisation of limited natural resources, raising the effectiveness of product manufacturing with high efficiency and low consumption of resources and a low (or even zero) production of emissions. Multinational corporations must adjust their management practices to adhere to national regulation and local standards (Jánošová \& Labudová 2019). Part of it lies in the prevention and decrease of waste production, and with it, the prevention and decrease of polluting substance sources, up to and including recycling, where resources are returned back into the economic cycle, a procedure that has an increasingly urgent practical significance.

Currently, these issues are highly topical not only in Slovakia, but all the developed countries of the world. For several years, various authors have delved into the circular economy as one of the tools for sustaining a healthy natural environment (Sauvé et al. 2016). One part of this field encompasses problem-solving within the context of waste management (Darnadyova 2019). The conversion of waste into reusable resources is also one of the basic goals of the plan for effective use of resources. It is necessary to note, that we need to pay the greatest amount of attention to reuse and recycling in particular.

The circular economy is a strategy of a long-term sustainable development through which one can create functional and healthy relations between the natural environment and people. It is understood as an opponent of the linear system. The basic principles of the circular economy are based on the idea that the product and material flows are once again returned into the production cycle after use, where they'll become resources important for the creation of new products and services. The goal is to prevent the multiplying of waste. Up until now, the solutions were based on the replacement of primary materials with secondary ones. Recycling was to be the way out of this situation. However, we can't consider this solution to be attractive, given that the overall process is considered as very demanding in terms of energy consumption. In general, we talk about the degradation of materials, which leads to an orientation of demand towards primary materials. With a circular economy, we move beyond the boundaries of recycling. Recycling is based on a renewing industrial system that leads to the termination of waste. It is precisely that 
the quality of the business environment considered the main factor of long-term economic competitiveness and long-term sustainable development of small and medium enterprises (Jánošová \& Labudová 2019). We therefore consider recycling to be the outer layer of a circular economy, even though it requires higher energy consumption than the inner layer of the circular economy. The circular economy should serve for the better use of a product's life cycle, and along with that, also minimize the needed energy consumption.

Part Six of the Constitution of the Slovak Republic (SR) delineates the right to the protection of the natural environment and cultural heritage. Article 44 states:

- Everyone has the right to an auspicious environment.

- Everyone is obliged to protect and enhance the environment and the cultural heritage.

- No one must endanger or damage the environment, natural resources, and the cultural heritage beyond the extent established by law.

- The state looks after an economical use of natural resources, ecological balance, and effective environmental care.

Details about the rights and obligations based on sections (1 to 4) are stated by law. The law which specifies the particulars concerning the rights and obligations according to sections 1 to 4, actually represents a series of laws, especially law no. 17/1992 of the Collection of Laws (CoL) on the natural environment, law no. 127/1994 CoL on the assessing of impacts on the natural environment as altered and amended, law no. 309/1991 CoL on air protection from polluting substances /clean air act/ as altered and amended, law no. 76/1998 CoL on the protection of the Earth's ozone layer and its amendment in law no. 455/1991 CoL on trade enterpreneurship /enterpreneurial act/ as altered and amended, law no. 223/2001 CoL on waste and the changes and amendments to certain laws, law no. 184/2002 CoL on waters and the changes and amendments to certain laws /water protection act/, law no. 543/2002 CoL on the protection of nature and the landscape, law no. 15/2005 on the conservation of wildlife species by regulating trade with them and the changes and amendments to certain laws, law no. 245/2003 $\mathrm{CoL}$ on integrated prevention and environmental inspection of pollution and the changes and amendments to certain laws, as altered and amended, and the changes and amendments to certain laws, law no. 205/2004 CoL on the gathering, storage and spread of information on the natural environment and the changes and amendments to certain laws, law no. 572/2004 CoL on the trading with emission quotas and the changes and amendments to certain laws, and law no. 491/2005 CoL on the environmental verification and registration of organisations within the 
scheme of the European community for environmental management and audit, and the changes and amendments to certain laws (Drgonec 2007).

Article 44 of the Constitution of the SR considers it the norm, which guarantees basic rights in connection with art. $51 \mathrm{sec}$. 1 . All basic rights, which are granted according to no. 44, it is possible to only demand them within the law, as documented in the provisions of art. 44. A situation that forms an exception is one, in which the SR acceded to the exercising of an international agreement with precedence over the laws of the SR according to art. 7 sec. 5 or art. $154 \mathrm{c}$ sec. 1 of the Constitution of the SR, or if there exists a legally binding act of the European Community and European Union art. $7 \mathrm{sec} .2$.

This connection is particularly special with regards to the topic of environmental protection. In the area of international conventions alone, the Slovak Republic had ratified 20 agreements of an international nature since 2006.

(a) Air quality protection conventions - Convention on Long-Range Transboundary Air Pollution - Geneva (Switzerland) convention, adopted 13 November 1979 in Geneva. The following protocols were approved as supplements to the aforementioned convention: The protocol added to the Convention on Long-Range Transboundary Air Pollution from 1979, the Protocol on the Long-term Financing of the Co-operative Programme for Monitoring and Evaluation of the Long-range Transmission of Air Pollutants in Europe (EMEP), was approved in Geneva on the 28 September 1984. It was followed by the Protocol to the Convention on LongRange Transboundary Air Pollution in 1979, on the decreasing of sulphur emissions or their transfer between previous state borders, the Protocol to the Convention on Long-Range Transboundary Air Pollutionm on the lowering of transboundary transfers by at least $30 \%$, Protocol to the Convention on Long-Range Transboundary Air Pollution in 1979, on decreasing the emissions of nitrous oxides or their transboundary transfers, Protocol to the Convention on Long-Range Transboundary Air Pollution in 1979, on further decreasing of sulphur emissions, Protocol to the Convention on Long-Range Transboundary Air Pollution on heavy metals, Protocol to the Convention on Long-Range Transboundary Air Pollution on persistent organic compounds, Protocol to the Convention on Long-Range Transboundary Air Pollution on the limiting of volatile organic compound emissions and theur transboudary transfer, and the Protocol to the Convention on Long-Range Transboundary Air Pollution on the decreasing of acidification, eutrophication and low level ozone.

The Framework Convention of the UN on climate change was adopted in New York on the 9 May 1992. The Kyoto Protocol was adopted in addition to the aforementioned convention. 
The Convention for the Protection of the Ozone Layer was signed in Vienna on the 22 March 1985. This convention also includes a range of signed protocols: The Montreal Protocol on Substances that Deplete the Ozone Layer, the Montreal supplementary protocol to the Montreal Protocol on Substances that Deplete the Ozone Layer, the London supplementary protocol to the Montreal Protocol on Substances that Deplete the Ozone Layer, the Copenhagen supplementary protocol to the Montreal Protocol on Substances that Deplete the Ozone Layer, and the Peking supplementary protocol to the Montreal Protocol on Substances that Deplete the Ozone Layer.

The Stockholm Convention on Persistent Organic Pollutants was signed in Stockholm on the 22 May 2001.

(b) Water protection conventions - include the Convention on the Protection and use of Transboundary Watercourses and international lakes, and the International Commission for the Protection of the Danube River.

(c) Nature conservation conventions - these include the Convention on Biological Diversity, which itself includes the signing of the Cartagena Protocol on Biosafety, Convention on the Conservation of European Wildlife and Natural Habitats, Convention on Wetlands of International Importance especially as Waterfowl Habitat, Convention on the Conservation of Migratory Species of Wild Animals - it also includes the Agreement on the Conservation of Populations of European Bats, The Agreement on the Conservation of African-Eurasian Migratory Waterbirds, Convention on International Trade in Endangered Species of Wild Fauna and Flora, Convention Concerning the Protection of the World Cultural and Natural Heritage, International Convention for the Regulation of Whaling and its Protocol of changes and amendments and the European Landscape Convention.

(d) Cross - sectional conventions include the United Nations Economic Commission for Europe Agreement about assessing the transboundary effects on the natural environment, Agreement on transboundary movement of hazardous waste and their final disposal - which itself includes the signing of the Amendment to the Basel Convention on the Control of Transboundary Movements of Hazardous Wastes and Their Disposal, Convention on the Transboundary Effects of Industrial Accidents, The Framework Convention on the Protection and Sustainable Development of the Carpathians, Convention on Access to information, Public Participation in Decision-making and Access to Justice in Environmental Matters - the Aarhus Convention, and the Convention for the establishment of a European Organisation for the Exploitation of. Meteorological Satellites (EUMETSAT). 
It is apparent that the individual regulations in article 44 also state obligations in addition to the rights. The legal subject of the aforementioned article 44 section 2 is everyone. However, in this article, paragraph 3 does not continue to use the word everyone, but adjusts the subject that is subordinate to the legal arrangement in this constitutional norm. The use of the wording of „no one“ is based on language rules, the wording of „no one“ identical in meaning with the word „everyone“, as stated in sections 1 and 2. If we mention the subject, it is necessary to also delineate the subject of protection, i.e. the natural environment, natural resources and cultural monuments.

The protection according to the Constitution of the SR in art. 44 sec. 3 cannot be understood as absolute. It is connected with the endangering and damaging of protected objects, to an extent that is higher than stated by the law.

Sec. 4 of the given article regulates the standing of the state in the areas ennumeratívely described by the constitution, related to the subject of the wording in article 44. Based on this specific provision, the state pays attention to the considerate utilisation of natural resources, to ecological balance and effective care for the natural environment. It also simultaneously ensures the protection awarded to species of wild flora and protection awarded to wild fauna. The article further states, that these activities do not need to be carried out directly - by national, central or local authorities. For the sake of the wording of this article, the state can transfer the realization of the goals to authorities of administrative areas, or to entities of private law. However, it is necessary to uphold the prescribed quality - to considerately utilise natural resources (Drgonec 2007).

The following article of the Constitution of the SR also grants the basic rights in connection to art. $51 \mathrm{sec}$. 1. It is only possible to demand all basic rights, which are granted by art. 45, within those laws, that carry out the provisions of the article.

The right to information, related to the evaluation of the state of the natural environment, is identical with the general right to information, as awarded by article 26, which states that the authorized person is granted the same forms of exercising of this right, i.e. to seek out, accept and expand information on the state of the environment. The Constitution of the SR says, that this right is not limited only to the receiving of information. The given information must be provided in time and to its fullest extent. We consider information pertaining to the environment to be of a timely nature only when there is a possibility to use it in procedures beneficial to the natural environment. This might include information of a negative nature. The subject of this information 
can be the state of the environment, the causes behind the state of the environment and the consequences of the state of the environment (Drgonec 2007).

The goal of marketing comunication is to inform, to acquaint the public about the quality, usefulness and uses of a product. Besides this goal, it is also necessary to react to the demands of consumers. The essence of communication activities is to influence the shopping behaviour of consumers, with the help of communication system tools. The traditional tools of marketing communication include: advertising, sales promotion (merchandising), public relations and personal sales.

Marketing communication is significantly influenced by digital media, due to its functioning via a common virtual space. This is despite the fact that we no longer consider the Internet to be a new technology, but instead consider it a form of networked infrastructure, because its accessibility is understood as a right of the people. „Thanks to the trends of the digital age as well, marketing communication has broad options for spreading marketingcommunication messages. This is provided by the new opportunities offered by the expansion of mass communication and information technologies, but also the efforts of marketers to draw the public's attention with new, unconventional forms of presentation and staging original advertising and promotional campaigns. (...) The transfer of information becomes economically more advantageous, more flexible time-wise and the option of receiving feedback allows for a more accurate targeting of the marketing product." - as mentioned by Rajčák in the publication Marketing communication in the digital age (Rajčák 2013).

\section{Marketing research}

For the purposes of the research, it is immensely important to organise a good quality collection and processing of data. To supplement the information database, it was helpful to carry out marketing research, which occured in three phases. As part of the quantitative research, this effort consisted of secondary data collection, through the study of theoretical source materials including materials of various authors, resources of the Statistical Office of the Slovak Republic, or articles in science magazines. It was then followed by the collection of primary data.

\section{Research phase}

The survey was carried out between the 20 September and 20 October 2018. The survey was carried out in two renditions. The electronic rendition was shared publicly on the Facebook social network. The second rendition was carried out by personal contact with a group of randomly selected respondents. The stated renditions were created based on the broad range of 
the target group, the respondents ranging from 18 to 65 years old. The greater number of respondents was recorded on the social network, older respondents were surveyed through a random selection in the shopping centres of the Trnava region. From the point of view of our survey, it was necessary that all of the queried respondents be citizens from within the Trnava region. The size of the selected sample was calculated with the help of a formula. The basic sample consisted of the inhabitants of the Trnava region, with an age range between 18 and 65 years of age. We based our survey on the statistical data from the Statistical Office of the Slovak Republic, with the basic sample consisting of 420,867 people.

\begin{tabular}{lrr}
\hline The level of reliability & Margin of error percentage & The size of the basic sample \\
\hline $95 \%$ & $5 \%$ & 420,867 \\
recommended size & $\mathbf{3 8 5}$ & \\
of the selected sample & & \\
\hline
\end{tabular}

\section{Research phase}

In this phase of the research, the focus was on defining the relationship of the individual materials from selected clothing industry products. The samples for chemical analysis were chosen. With the acquired data, we subsequently ascertained, whether there exists a dependency between the level of recycling and the price of selected textile products. To this end, a correlation and regression analysis in MS Excel software was used.

\section{Research phase}

This phase was focused on acquiring relevant data from the respondents on the subject of shopping choice, the shopping behaviour of consumers within the conditions of a circular economy. The acquired data was subsequently evaluated based on the evaluation criteria determined in advance, and then charted graphically. The results formed an information base in the creation of recommendations for the improvement of the current status of implementing the principles of a circular economy in Slovakia. The subsequent observance of the given principles will help secure the protection of the natural environment.

\section{Results and discussion}

Because the range of products is very wide and the goal was to research the individual production areas in greater detail, the authors have decided to focus their following research on clothing industry products used by sportsmen. This narrow specialisation is intentionally aimed at 
products that are used in daily life on a stable basis. In the conclusion, the results of the research will be generalised to all products of the clothing industry.

The target group of the survey was divided into three age categories, specifically, people between 18 to 30 years old constituted 24\%, the group between 31 and 50 years of age constituted $39 \%$, and the last group, in the age range of 51 to 65 years was represented by $37 \%$. Thanks to this percentual division as well, it becomes clear that all the categories in the target group were to be addressed with almost the same amount of respondents.

The respondents were asked about the frequency of their shopping for clothes, clothing industry products. Based on the evaluation of replies, it was found out that $45 \%$ of the queried shops for clothes at least once $(1 \mathrm{x})$ every 3 months. This was followed by a group of 96 respondents, which goes shopping once $(1 \mathrm{x})$ a month. 85 of the queried respondents shops at least once $(1 \mathrm{x})$ every six months, and the group with the lowest frequency of shopping, only once (1x) in a year, constitutes $8 \%$.

Whether the respondents from the selected sample follow the individual communication tools during the process of shopping for clothes was surveyed. It is interesting that as many as 162 of all queried respondents did not know how to answer the question. 119 respondents replied positively and 104 respondents commented that communication tools play no role in their shopping process.

The attention was directed at ascertaining the knowledge of the queried respondents on the individual principles of the circular economy, on the sample of clothing industry products. The most surprising find for us was that as many as 177 respondents did not know the features of the circular economy in the clothing industry. 123 respondents had a grasp on this area and 85 of the queried respondents had no knowledge at all on the working principle of a circular economy.

\section{Conclusion}

Summing up the results of this survey it can be concluded that the policy of the European Union and its individual states is satisfactory. Adopted legislative measures are at a sufficient level, EU countries responding to initiatives and legislative measures issued by the European Union and revising them to national conditions. Also Slovakia, based on the results of the survey is at a sufficient level in this area. The biggest deficiency that we found in the research is insufficient verification of legislative measures issued by Slovakia. As an example, here are a few pictures that point to non-compliance with Slovak legislative measures. 
Picture 1. Illegal dump

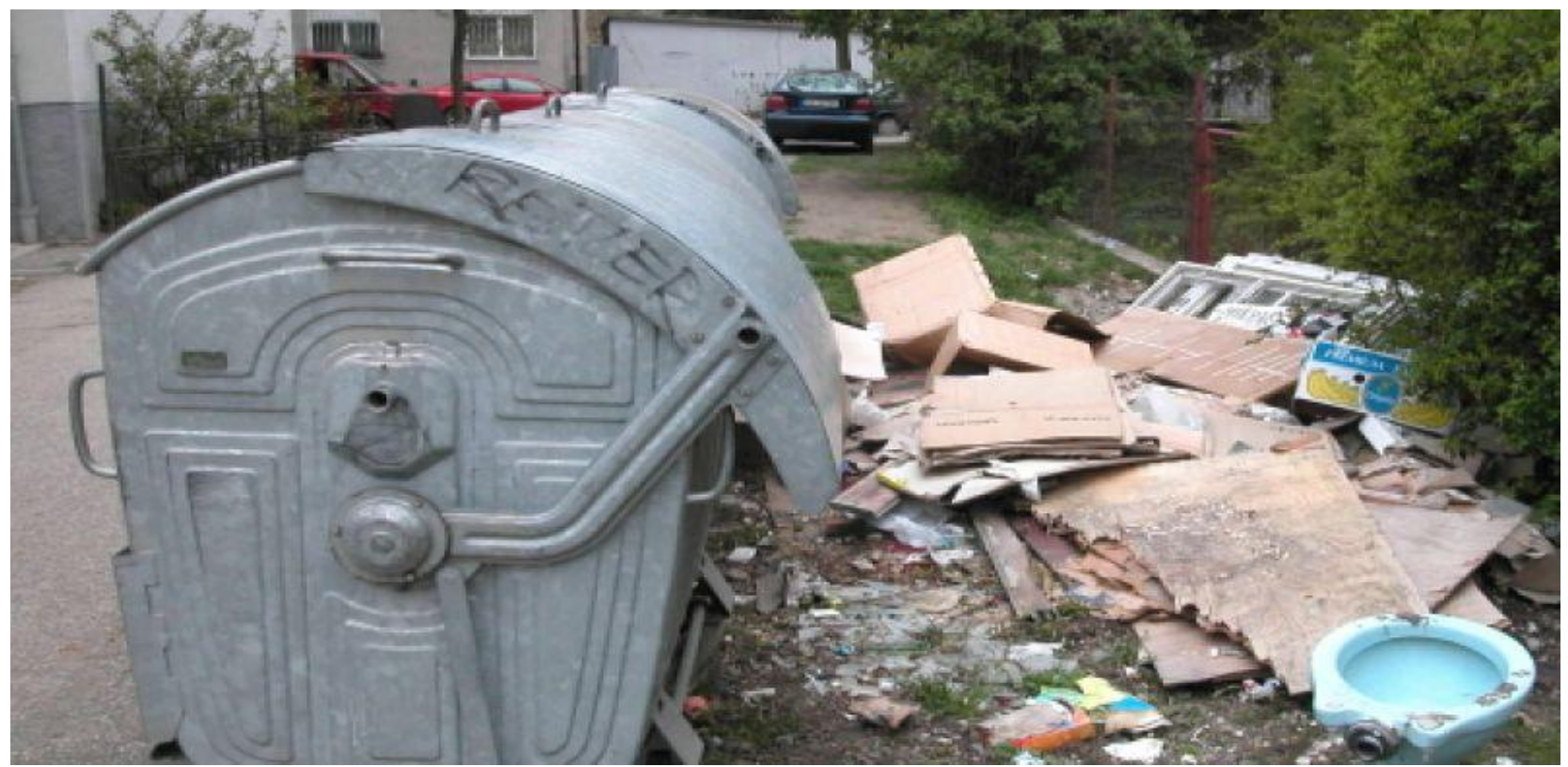

Source: own work.

Picture 2. Pollution of watercourses

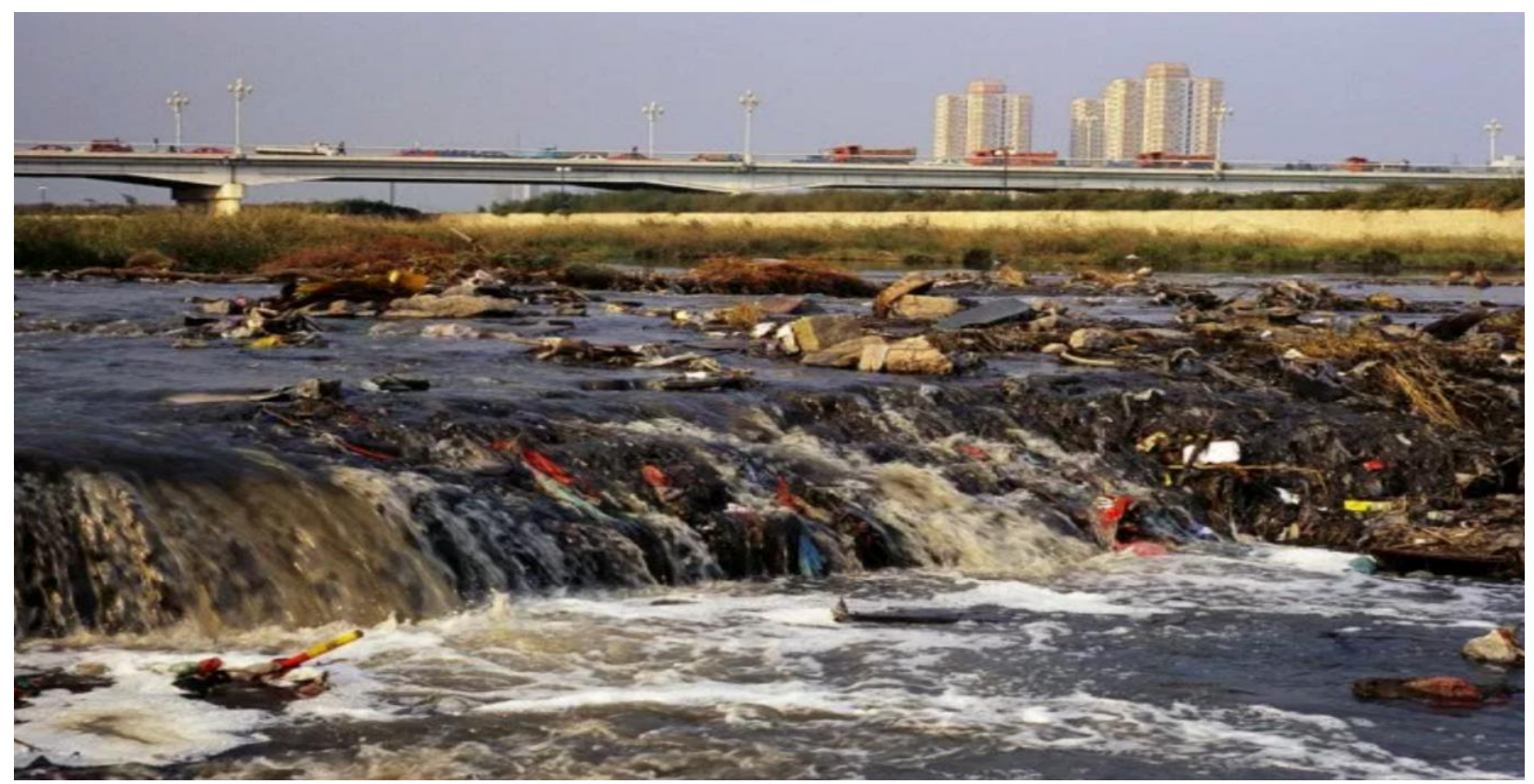

Source: own work.

Finally, it is necessary to draw attention to the fact that in the fight against waste management it is absolutely necessary to ensure the enforceability of the law, to implement all political, legislative guidelines into practice. We are aware that this process has a long-term character, but it is up to people to improve the situation. 
In the current situation, not only governments, but also the public, including individual companies, are beginning to recognize the need to introduce long-term sustainable approaches to economic development. This results in the fact that even customers demand the guaranteeing of a competitive advantage, they demand non-faulty products, suitable for both their health concerns and for the natural environment. In the present, business owners in Slovakia are also beginning to utilise the tools of a circular economy and green innovations. The two greatest issues that emerge from our surveys are climate change and economic crises. The results hint that the rate of innovation and technological progress is currently at a very low level. Applying the individual models of a circular economy is a long-term process and in Slovakia, currently at a very weak level. The results hint that innovations are the basic element of a cyclical type of economy.

Nature and natural resources, which are increasingly threatened by depletion and pollution with growing world population, are becoming the focus of attention around the world. Based on a large number of theoretical and practical knowledge of experts, we have tried to approach the issue of the circular economy as a key concept towards a sustainable economy.

\section{Funding:}

The paper is an output of the research project supported by the Grant Agency of the Ministry of Education of the Slovak Republic and the Slovak Academy of Sciences (VEGA) No. 1/0078/18 titled Aspects of Marketing Communication in the Management Processes of Circular Economy.

\section{References:}

Darnadyová, A. (2014). Kruhová ekonomika [Circular Economy]. Odpadové Hospodárstvo, 4(8).

Drgonec, J. (2007). The Constitution of the Slovak Republic: Comment. Bratislava: Heuréka.

Euractiv (2015). Slováci triedia odpad najmä slovne [The Slovaks sort waste mainly verbally]. https:/euractiv.sk/section/zivotne-prostredie/news/slovaci-triedia-odpad-najma-slovne-024369/ (12/11/2019).

Jánošová, D., \& Labudová, L. (2019). Analysis of support and identification of barriers to SMEs in Slovakia and in the Czech republic. Serbian Journal of Management, 14(2), 437-53.

Rajčák, M. (2013). Marketingová komunikácia v digitálnom veku: Vybrané trendy, metódy a techniky [Marketing communication in the digital age: selected trends, methods and techniques]. Trnava: University of Ss. Cyril and Methodius.

Sauvé, S., Bernard, S., \& Sloan, P. (2016). Environmental Sciences, Sustainable Development and Circular Economy: Alternative Concepts for Trans-Disciplinary Research. Environmental Development, 17, 48-56. 